\title{
Organ Preservation Strategies After Neoadjuvant Chemoradiotherapy for Locally Advanced Rectal Cancer
}

\author{
Ri Na Yoo, Hyung Jin Kim \\ Division of Colorectal Surgery, Department of Surgery, St. Vincent's Hospital, College of Medicine, The Catholic University of Korea, Suwon, \\ Korea
}

Standard use of neoadjuvant chemoradiotherapy, total mesorectal excision, and postoperative adjuvant chemotherapy in locally advanced rectal cancer has tremendously improved oncologic outcomes over the past several decades. However, these improvements come with costs of significant morbidity and poor quality of life. Along with developments in imaging techniques, clinical experience and evidence have identified a certain subgroup of patients that have exceptionally good clinical outcomes while preserving quality of life. Driven by patient demand and interest in preserving quality of life, numerous organ preservation treatment strategies for managing rectal cancer are rapidly evolving. Herein, the flow of research in organ preservation strategies and counter arguments are discussed.

Keywords: Rectal neoplasms; Organ preservation; Quality of life; Induction chemotherapy; Consolidation chemotherapy

\section{INTRODUCTION}

For the past four decades, the vast improvement in the management of rectal cancer has been achieved based on the development of surgical techniques and the implementation of multimodal therapies. In the early 1980s, the report of 'Holy plane' in rectal cancer surgery elaborated a resection technique based on the embryologic development of the hindgut, named total mesorectal excision (TME) [1]. TME resulted in decreased positive circumferential resection margins, which ultimately reduced the local recurrence rate and improved survival outcome dramatically $[2,3]$. TME also relegated nonsphincter saving procedure, allowing a majority of patients to save anal sphincter [4].

In a similar timeframe, radiation therapy attracted the attention of many clinicians for treating locally advanced rectal cancer. Several clinical trials were conducted to investigate the effect of radia-

Received: January 31, 2019 • Accepted: April 15, 2019

Correspondence to: Hyung Jin Kim, M.D.

Division of Colorectal Surgery, Department of Surgery, St. Vincent's Hospital, College of Medicine, The Catholic University of Korea, 93 Jungbu-daero, Paldal-gu, Suwon 16247, Korea

Tel: +82-31-249-8316, Fax: +82-31-247-5347, E-mail: hj@catholic.ac.kr ORCID code: https://orcid.org/0000-0002-6315-714X

(C) 2019 The Korean Society of Coloproctology

This is an open-access article distributed under the terms of the Creative Commons Attribution NonCommercial License (http://creativecommons.org/licenses/by-nc/4.0) which permits unrestricted noncommercial use, distribution, and reproduction in any medium, provided the original work is properly cited. tion therapy in rectal cancer management. The results indicated that the superiority of preoperative radiotherapy for local control with better compliance with treatment and low toxicity [5-8]. Later trials demonstrated the concurrent chemotherapy with fluorouracil and leucovorin given with radiotherapy significantly boosted the local control in locally advanced rectal cancer $[9,10]$. These reports also showed an enhanced rate of pathologic complete response and reduced local recurrence rate as low as 5.3\%. Therefore, accurately guided by exquisite diagnostic imaging, the multimodal approach using neoadjuvant chemoradiotherapy (nCRT) and subsequent TME is now adopted widely in rectal cancer management.

The current primary approach for managing rectal cancer is a radical resection. It requires high-end surgical training for meticulous TME with nerve-sparing technique. Moreover, radical rectal resection is a major procedure with a substantial risk of perioperative morbidity and mortality, particularly for the elderly [11]. Also, patients who received radical resection cannot avoid ample loss of anorectal, sexual, and urinary function, which eventually leads to poor quality of life [12-14]. As clinical data on patients treated with rectal cancer accumulates, a particular subgroup of patients shows a complete response or non-response to multimodal treatment. This presents a challenge to identify treatment modalities that could maintain or improve the oncological outcome while preserving quality of life.

This article discusses organ preservation strategies after nCRT 
for managing locally advanced rectal cancer, clinical T3 and above or positive mesorectal lymph node.

\section{NEOADJUVANT CRT AND ADJUVANT CHEMOTHERAPY}

It is well known that nCRT can downsize or downstage a tumor, but can also achieve a pathological complete response (pCR) defined as the complete absence of cancer cells in the resected specimen. The rate of pCR is reported up to $10 \%-32 \%$ of patients [1517]. The prognosis after obtaining pCR is usually excellent, and is often used as a surrogate of oncologic outcome [18]. Two metaanalyses on $\mathrm{pCR}$ following preoperative CRT in rectal cancer sought to identify factors that could increase the rate of pCR. These studies revealed that the use of a continuous infusion of 5 -fluorouracil, the use of 2 drugs and high radiation doses were associated with higher rates of pCR [16, 17]. Noninferiority, phase 3 , randomized trials that compared capecitabine to 5-fluorouracil in CRT showed that capecitabine could be used as an alternative in neoadjuvant or adjuvant CRT regimens [19, 20]. Several other trials also investigated the addition of oxaliplatin to 5 -fluorouracil based CRT as a radiosensitizer [20-22]. However, they failed to demonstrate the oxaliplatin as a radiosensitizer but only increased in toxicity; as a consequence, adding oxaliplatin to nCRT was not supported. Finally, although the rate of pCR was higher with increasing doses of radiation, a dose-response effect beyond $45 \mathrm{~Gy}$ was not recommended due to the lack of data $[16,17]$. In spite of achieving $\mathrm{pCR}$ and increasing disease-free survival, nCRT in clinical trials did not reduce the risk of systemic metastasis, and overall survival was not improved [23, 24].

Using the multimodal approach, the rate of local recurrence has been reported atonly $5 \%-6 \%$ in recent years [25], and it seems now less of the concern than developing distant metastasis. Toprevent distant metastases by eliminating circulating tumor cells and micrometastases, adjuvant chemotherapy has been recommended in patients with locally advanced rectal cancer treated with nCRT and TME [26]. This recommendation to patients with stage II or III rectal cancer is based on extrapolation of results from phase 3 trials of adjuvant treatment for colon cancer $[27,28]$ and data of patients with rectal cancer treated without preoperative radiotherapy or CRT [29]. Based on a systematic review and meta-analysis of adjuvant chemotherapy after preoperative radiotherapy and surgery in patients with rectal cancer, adjuvant chemotherapy for rectal cancer does not improve overall survival, disease-free survival, or distant recurrences in general [30]. In contrast, in patients with upper rectal cancer, adjuvant chemotherapy could be benefitial in terms of disease-free survival and distant recurrence [30]. Therefore, based onthe conflicting data, the benefit of adjuvant chemotherapy remains controversial with regard to clinical application.

In addition, concerns on patient compliance with adjuvant therapy have been raised. Nearly $30 \%$ of eligible patients had never initiated adjuvant chemotherapy [31], and less than half of these patients had received the full treatment without interruption or delays $[5,32,33]$. Postoperative complications including leakage, poor general condition, and slow recovery, problems with the temporary stoma, or refusal of treatment were the main reasons for withdrawing from the adjuvant therapy [34]. Evaluation on timing and efficacy of postoperative adjuvant chemotherapy demonstrated that each 4-week delay in treatment correlated with a $14 \%$ drop in overall survival [35]. Based on these data, it is clear that poor treatment compliance with adjuvant chemotherapy, regardless of the reasons, impedes patient survival, and other modes of delivering chemotherapy are needed. Therefore, the concept of delivering chemotherapy before surgery has been proposed to treat occult micrometastases earlier and increase treatment compliance, ultimately improving survival outcome [36]. Different methods and schedules for performing systemic chemotherapy before surgery are a current focus in clinical trials in rectal cancer management.

\section{MODE OF DELIVERING SYSTEMIC CHEMOTHERAPY AND pCR}

In the effort to improve disease control systemically and locally, induction therapy, dividing adjuvant chemotherapy and delivering a limited number of cycles before nCRT, and then providing the remaining postoperatively has been proposed to increase tumor response in patients with locally advanced rectal cancer [3741]. Theoretically, upfront chemotherapy allows the chemotherapeutic agents to reach the primary tumor directly when the vasculature is not disrupted either by radiation or surgery, which could optimize the tumor response to the chemotherapeutic agent optimally. The clinical trials of induction chemotherapy demonstrated no adverse effect that delayed treatment, increased pCR rate, and early identification of non-responders along with excellent treatment compliance $[16,18,36,42]$. The long-term oncologic outcome is not available yet since the therapeutic approach of induction chemotherapy is relatively recent. Based on the short-term outcome of the patients enrolled in clinical trials, the investigators anticipate sufficient survival gains to consider the induction chemotherapy as a viable option for locally advanced rectal cancer [42].

Another way of increasing pCR rate is adding a few cycles of systemic chemotherapy between CRT and surgery, known as consolidation therapy [43]. The results from a nonrandomized, phase II trial showed that consolidation chemotherapy with FOLFOX increased the pCR rate up to $37 \%$ while surgical complication was not different from the patients who underwent the standard treatment strategy composed of neoadjuvant chemoradiotherapy, TME, and then adjuvant chemotherapy [43]. Although the overall survival rate was not yet determined from the limited number of patients, the disease-free survival of the patients given to the consolidation chemotherapy during the waiting 
Table 1. Studies investigating consolidation chemotherapy

\begin{tabular}{|c|c|c|c|c|c|c|c|c|c|c|}
\hline Study & Design & $\begin{array}{l}\text { No. of } \\
\text { patients }\end{array}$ & $\begin{array}{l}\text { CRT } \\
\text { regimen }\end{array}$ & $\begin{array}{l}\mathrm{NAC} \\
\text { regimen }\end{array}$ & $\begin{array}{l}\text { Adjuvant } \\
\text { CTx }\end{array}$ & $\begin{array}{c}\text { pCR } \\
\text { rate }(\%)\end{array}$ & Compliance & $\begin{array}{c}\mathrm{R} 0 \\
\text { resection } \\
\text { rate }(\%)\end{array}$ & $\begin{array}{c}\text { Surgical } \\
\text { complication } \\
\text { rate }(\%)\end{array}$ & $\begin{array}{l}\text { Survival } \\
\text { outcome }\end{array}$ \\
\hline \multirow[t]{3}{*}{$\begin{array}{l}\text { Garcia-Aguilar } \\
\text { et al. [43] }\end{array}$} & $\begin{array}{l}\text { Phase } \| \\
\text { nonrandomized }\end{array}$ & 259 & $\mathrm{CRT}+5 \mathrm{FU}$ & None & mFOLFOX $(8 \times)$ & 18 & Not reported & 98 & 15 & Not reported \\
\hline & 4-arm & & $\mathrm{CRT}+5 \mathrm{FU}$ & mFOLFOX6 (2x) & mFOLFOX (6x) & 25 & $\begin{array}{l}\text { 82\% completed } \\
\text { NAC }\end{array}$ & 100 & 6 & Not reported \\
\hline & & & $\mathrm{CRT}+5 \mathrm{FU}$ & mFOLFOX6 (6x) & mFOLFOX (2x) & 36 & $\begin{array}{l}\text { 77\% completed } \\
\text { NAC }\end{array}$ & 100 & 9 & Not reported \\
\hline $\begin{array}{l}\text { Polish II trial } \\
\text { [45] }\end{array}$ & $\begin{array}{l}\text { Phase III } \\
\text { randomized } \\
\text { 2-arm }\end{array}$ & 515 & RT $(5 \times 5$ Gy $)$ & $\begin{array}{l}\text { FOLFOX4 } \\
\text { (3 cycles) }\end{array}$ & Not reported & 16 & $\begin{array}{l}63 \% \text { completed } \\
\text { NAC }\end{array}$ & 77 & 29 & $\begin{array}{r}3-y r \text { DFS, } 53 \% \\
3-y r \text { OS, } 73 \%\end{array}$ \\
\hline Zhu et al. [47] & $\begin{array}{l}\text { Phase II } \\
\text { single-arm }\end{array}$ & 42 & $\mathrm{CRT}+\mathrm{CAPOX}$ & Cape $(1 x)$ & CAPOX (6-8x) & 17 & $\begin{array}{l}100 \% \text { com- } \\
\text { pleted NAC }\end{array}$ & 92 & 16 & $\begin{array}{r}3-y r \text { DFS, } 57 \% \text {; } \\
3-y r \text { OS, } 66 \%\end{array}$ \\
\hline
\end{tabular}

CRT, chemoradiotherapy; NAC, neoadjuvant chemotherapy; CTx, chemotherapy; pCR, pathologic complete response; RT, radiotherapy; 5-FU, 5-fluorouracil; Cape, capecitabine; CAPOX, capecitabine/oxaliplatin; DFS, disease-free survival; mFOLFOX6, modified 5-fluorouracil, leucovorin, and oxaliplatin; Gy, gray; OS, overall survival; $\mathrm{RO}$, microscopically clear resection.

period for surgery significantly improved [44]. Interestingly, the rate of $\mathrm{pCR}$ increased along with the increasing interval between the CRT and surgery while extended cycles of FOLFOX could be given instead of initially intended cycles, as shown in Table 1 [4547]. As demonstrated by the remarkable compliance of patients along with improved oncologic outcome, the neoadjuvant consolidation chemotherapy after CRT in rectal cancer treatment is another attractive treatment approach for patients with rectal cancer.

The challenges for overcoming the limitations of neoadjuvant CRT in overall survival gain have distinguished a certain patient subgroup with the excellent oncologic outcome. This particular subgroup is presumed to have tumors with distinct characteristics and behaviors that result in a different risk of recurrence and survival probabilities. Diagnostic methods to identify patients that have profiles fortumors with low risk of recurrence and good survival probability are currently under investigation. If applicable, the quality of life in the patient who has rectal cancer may be preserved by skipping a radical rectal resection.

\section{"WATCH AND WAIT" AND "SALVAGE SURGERY”}

TME has been the critical element in the multimodal treatment for patients with rectal cancer. However, based on the observation of the clinical and oncologic outcome of patients who obtained pCR after neoadjuvant CRT, some surgeons have contested the multimodal algorithm of neoadjuvant CRT, TME then postoperative chemotherapy. In 2004, the Brazilian group led by HabrGama et al. [48] published a retrospective study on the patients managed nonoperatively after achieving significant tumor regression via neoadjuvant CRT, asserting the concept of organ preservation in rectal cancer management. Although the surgical and oncological society predominately reacted with strong objection and skepticism at first, a few years later other groups reported similar findings with a similar therapeutic approach, demonstrating reproducibility $[49,50]$. Although these articles exhibited a considerable variation in treatment protocols and nuances of the study population, an organ preservation strategy, particularly for low rectal cancer, has gained the interest of many clinicians and academia, which further supports a focus on avoiding postoperative severe morbidity and poor urinary, sexual, and bowel function after a radical rectal surgery.

In patients with locally advanced rectal cancer, tumor response to $\mathrm{nCRT}$ varies widely, and tumor regression grade (TRG) is considered an essential prognostic factor in survival outcome [51]. When a tumor is no longer detectable on various diagnostic modalities including digital rectal exam (DRE), endoscopy, transrectal ultrasonography (TRUS), or magnetic resonance image (MRI), it is referred to as a complete clinical response (cCR), and nonoperative management with strict follow-up can be offered [52]. The highest $\mathrm{CCR}$ rate after the standard regimen of nCRT, reported by Habr-Gama et al. [53], was $49.2 \%$. Other retrospective 
studies reported cCR rate from $11 \%$ to $16 \%$ [54-57]. The discrepancy in the rate of cCR is probably due to different definition and diagnosis of cCR made by investigators as well as the inclusion criteria in each retrospective study. In other prospective studies including $\mathrm{T} 2$ and $\mathrm{T} 3$ rectal cancers on watch and wait policy, the $\mathrm{CR}$ rate, either $\mathrm{CCR}$ or $\mathrm{pCR}$, was even much higher, reaching $67.1 \%$ to $78.4 \%$, when consolidation chemotherapy or endorectal brachytherapy was given $[53,58]$.

The incidence of regrowth was reported from $5 \%$ to $34 \%$, and most tumor regrowth occurred within the first 2 years [49, 56, 58]. The incidence of systemic recurrence was reported from $5 \%$ to $18 \%$, relatively low, accordant with the good prognosis of the patients with pCR [51]. The recently published systemic review and pooled analysis on the oncologic and survival outcome in watch and wait approach demonstrated that the pooled 3-year cumulative rate of local regrowth was estimated to be $21.6 \%$, and the 1- and 2-year cumulative regrowth rates were $11.7 \%$ and $18.2 \%$ [59]. The pooled 3-year overall survival rate was $93.5 \%$, and the 3-year nonregrowth, the disease-free survival rate was $89.2 \%$. In terms of local recurrence located outside the mesorectal fascia, only $2.7 \%$ was reported. The authors suggested that delayed surgery would be feasible in the majority of patients with regrowth. Therefore, the therapeutic option of organ preservation in a particular subgroup of patients with rectal cancer may not be so worrisome.

The most critical aspect of the organ preservation approach is the accurate clinical assessment of tumor response and timing of the assessment [52]. The assessment methodology is mostly based on the finding of clinically disappeared tumor mass on DRE and the direct visualization of rectal mucosa left only with scar tissue by endoscopy [48]. Most studies on watch and wait policy reported CCR based on the endoluminal assessment by DRE and endoscopy with or without biopsy [59]. As imaging technology develops, other modalities, including TRUS, abdominopelvic computed tomography, pelvic MRI, 18-fluorodeoxyglucose positron emission tomography (PET-CT), have been used additionally to increase the detection rate of cCR. Development in imaging technique brought out high-resolution MRI which allows for differentiation between fibrosis and residual disease [49, 60-62]. Based on the tumor regression grade measured by MR imaging, the pCR could be identified ten times more, compared with clinical assessment by DRE or endoscopy [63]. However, the value of MRI in restaging after nCRT is still controversial. It is necessary to resolve heterogeneity in the interpretation of various modes of MR imaging technique for restaging rectal cancer after nCRT [64]. The TRIGGER trial, a multicenter, open, interventional, randomized control feasibility study, is ongoing to validate the assessment of tumor response based on MRI-derived tumor regression grading system shortly named magnetic resonance tumor regression grade (mrTRG) [65]. As depicted in the schema of Fig. 1 , two prospective subtrials compose the intervention arm based on the mrTRG: the good-response group and the poor response group. The good response group follows the nonoperative approach upfront systemic chemotherapy before surgery. The result of this study will provide a whole lot of vital information regarding the role of MRI in organ preservation strategies for rectal cancer treatment.

Surveillance protocol in watch and wait approach varied greatly in follow-up schedule. Patients were examined in every one to three months by DRE and endoluminal assessment with endoscopy while imaging studies, such as CT scan, MRI or PET-CT scan, were conducted in every 3 to 6 months, shown in Table 2 . After the initial assessment post nCRT, patients with cCR were extensively re-assessed in the first two years. The pooled analysis by Dattani et al. [59] demonstrated $61.8 \%$ of all local regrowth presented in the first year of surveillance, with diminishing frequency thereafter, such that only $3.8 \%$ regrowth were detected beyond 3 years. These data suggest that surveillance protocol for watch and wait approach should include close follow-up during the first 1 to 2 years for observation, and patients should be able to readily adhere to the strict follow-up schedule.

Adding a local excision of the remaining scar can be an option for organ preservation. The advantage would be histological confirmation of a complete response. A multicenterd, nonrandomized trial evaluating the feasibility of transanal endoscopic microsurgery (TEM) in early distal rectal cancer demonstrated TEM could be used for accurate assessment of pathological response in case of a complete clinical response after nCRT [66]. A recent update on the oncological outcome in this CARTS study revealed that the local recurrence in TEM group was not difference from that in TME group, $9 \%$ vs. $7.7 \%$; the 5 -year disease-free survival for TEM group was $81.6 \%$ [67]. Also, a randomized controlled trial comparing the oncological outcome of TEM to laparoscopic TME for the treatment of patients with clinical stage T2 N0 M0 after nCRT suggested TEM had similar local recurrence rate, systemic metastasis, and disease-free survival [68]. However, a systematic review and meta-analysis on local excision after nCRT in early rectal cancer demonstrated local recurrence exceeded $20 \%$ in local excision group, and the authors implied probably reduction in long-term survival for the patients who did not achieve $\mathrm{pCR}$ [69]. In this review, the pooled local recurrence for ypT0 was $4 \%$, but rising to $12.1 \%$ for ypT 1 and $23.6 \%$ for ypT2 tumors. Therefore, the authors insisted that for oncological safety, local excision alone should only be considered a potential curative treatment if a pCR has been obtained.

Besides the oncological safety, other issues regarding local excision after nCRT include toxicity from chemoradiation therapy and postoperative complication arising from the unhealing rectal wound after nCRT. In current standard of care, early rectal cancer does not require nCRT before surgery. However, previous studies had reported mortality after nCRT, owing to toxicity from nCRT $[66,70]$. Also, patients reported grade 3 to 4 toxicity during nCRT [66]. Thus, giving nCRT to patients with early rectal cancer should carefully be reviewed about possible chemotoxicity and 


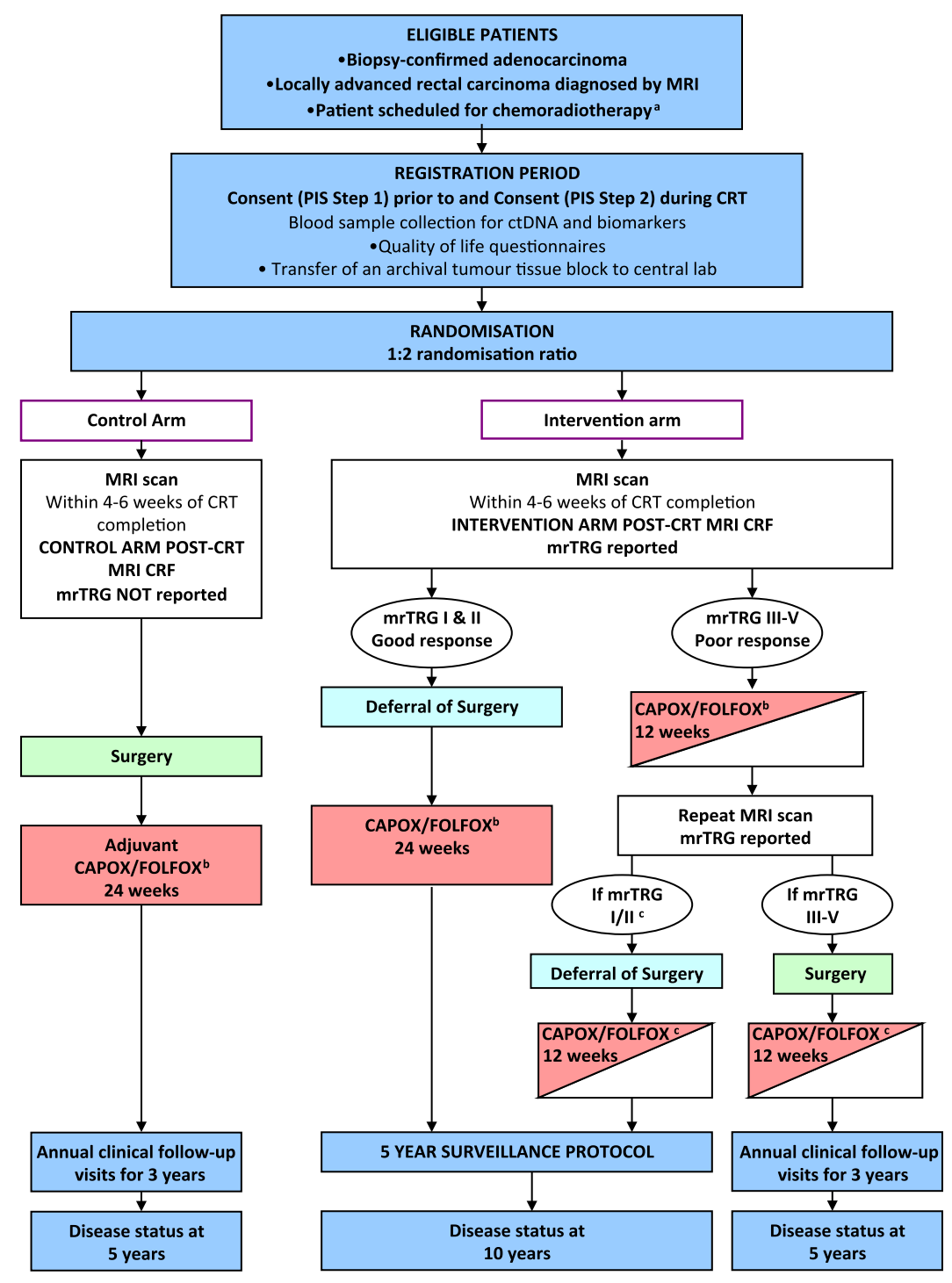

Fig. 1. The Magnetic resonance tumour regression grade as a novel biomarker to stratify management of good and poor responders to chemoradiotherapy: a rectal cancer multicentre randomised control trial (TRIGGER trial) is a multicenter, open, interventional, randomized control feasibility study to validate assessment of tumor response based on magnetic resonance imaging (MRI)-derived tumor regression grading system, named mrTRG [65]. CRT, chemoradiotherapy; mrTRG, magnetic resonance tumor regression grade; CRF, case report form; PIS, patient information sheet; CAPOX, capecitabine with oxaliplatin; FOLFOX, 5-fluorouracil (5-FU), leucovorin, and oxaliplatin. ${ }^{\text {a} S c h e d u l e d ~ t o ~ r e c e i v e ~}$ 45 Gy-55 Gy long-course radiotherapy. ${ }^{\text {b}}$ Treatment decision should be made prior to registration (planned choice is a randomisation stratification variable). Medical oncologist may choose to use CAPOX or FOLFOX, or signle-agent capecitabine or 5-FU if concomitant use of oxaliplatin is contraindicated. 'Patient defers surgery then the remaining 12 weeks of chemotherapy should be given as soon as possible following the repeat MRI scan and multidisciplinary team meeting.

necessity of radical surgery in case of poorly responsive tumor.

The incidence of postoperative complication and morbidity was $23.2 \%$ in the overall pooled data [69]. The most frequent complications were suture line dehiscence and rectal pain with the rate of $10 \%$. Among them $13.7 \%$ required operative re-intervention including diverting loop stoma, transanal re-suturing, anal stenosis, transsacral wound debridement, and abdominoperineal resec- tion [69]. A prospective study on the postoperative outcome after TEM following nCRT in cT2 and T3 rectal cancer reported $44 \%$ immediate complication of Clavien-Dindo classification grades II and III including rectal pain, bleeding, fistula, and peritonitis, and the hospital readmission rate was $30 \%$ [71]. In this report, the wound dehiscence was observed in $47 \%$. Late complication arising after postoperative 30 days was also reported, which included 
Table 2. Surveillance protocol of watch and wait approach

\begin{tabular}{|c|c|c|c|}
\hline Study & No. of patients & Surveillance protocol & Follow-up time (mo) \\
\hline \multirow[t]{4}{*}{ Smith et al. [50] } & 32 & 1st year & $28(9-70)$ \\
\hline & & -every 3 months: DRE and sigmoidoscopy & \\
\hline & & 2nd year & \\
\hline & & -every 4 to 6 months: DRE and sigmoidoscopy & \\
\hline \multirow[t]{7}{*}{ Habr-Gama et al. [53] } & 90 & 1st year & $60(12-233)$ \\
\hline & & -every 1 to 2 months: DRE and sigmoidoscopy & \\
\hline & & -every 2 to 3 months: serum CEA & \\
\hline & & -every 6 months: C/A/P CT scan, pelvic MRI and/or TRUS & \\
\hline & & 2nd year & \\
\hline & & -every 3 months: DRE, sigmoidoscopy, serum CEA & \\
\hline & & -annual: C/A/P CT scan, pelvic MRI and/or TRUS & \\
\hline \multirow[t]{5}{*}{ Lai et al. [55] } & 16 & 1st year & $46(14-80)$ \\
\hline & & -every 3 months: DRE, sigmoidoscopy, serum CEA & \\
\hline & & 2nd year & \\
\hline & & -every 3 months: DRE and sigmoidoscopy, serum CEA & \\
\hline & & Pelvic MRI, TRUS, A/P CT scan, chest X-ray 6 months after nCRT and annually thereafter & \\
\hline \multirow[t]{2}{*}{ Renehan et al. [56] } & 129 & 1st and 2nd year & $33(19-43)$ \\
\hline & & $\begin{array}{l}\text {-every } 4 \text { to } 6 \text { months: DRE, examination under anesthesia or endoscopy, C/A/P CT scan, } \\
\text { serum CEA, Pelvic MRI }\end{array}$ & \\
\hline \multirow[t]{6}{*}{ Vaccaro et al. [57] } & 23 & 1st year & $46(10-119)$ \\
\hline & & -every month: DRE, sigmoidoscopy & \\
\hline & & 2nd year & \\
\hline & & -every 2 months: DRE and sigmoidoscopy & \\
\hline & & -every 3 to 6 months: pelvic MRI, C/A/P CT scan & \\
\hline & & In some patients, PET scan was included. & \\
\hline \multirow[t]{6}{*}{ Appelt et al. [58] } & 40 & 1st year & $24(8-49)$ \\
\hline & & -every 2 months: DRE, sigmoidoscopy & \\
\hline & & -every 4 months: PET scan & \\
\hline & & 2nd year & \\
\hline & & -every 3 months: DRE, sigmoidoscopy & \\
\hline & & -every 6 months: PET scan & \\
\hline
\end{tabular}

DRE, digital rectal examination; CEA, carcinoembryonic antigen; C/A/P CT, chest/abdomen/pelvis computed tomography; MRI, magnetic resonance imaging; TRUS, transrectal ultrasonography; nCRT, neoadjuvant chemoradiation therapy; PET, positron emission tomography.

stenosis requiring general anesthesia for rectal dilatation and seminalvesicle fistula treated with oral antibiotics. The authors warned of that the use of TEM after nCRT would result in a significant morbidity, sometimes requiring invasive procedures. Altogether, local excision after neoadjuvant CRT as an organ-preserving strategy in rectal cancer treatment may play a role in highly selected patients. However, considerable morbidity from local excision and possible mortality from chemoradiation should be accounted before offering.

As previously discussed, the risk of regrowth is high in the first two years. If regrowth is detected, the standard treatment is TME [72]. The investigators studying organ preservation strategy insist that local regrowth detected early with sufficient follow-up can be treated adequately by salvage surgery [72]. A recently published systematic review on the outcome and salvage surgery following organ-preservation strategy shows that $69.2 \%$ of "watch and wait" group exhibited persistent $\mathrm{cCR}$, and salvage surgery was possible in $83.8 \%$ in patients who developed tumor regrowth [73]. Although the overall survival and disease-free survival between patients who received immediate surgery and the "watch and wait" 
Table 3. Ongoing trials investigating TNT approach and organ preservation

\begin{tabular}{|c|c|c|c|c|c|c|}
\hline TNT type & Trial & Design & $\begin{array}{l}\text { No. of } \\
\text { patients }\end{array}$ & Arms & $1^{\circ}$ endpoint & $2^{\circ}$ endpoint \\
\hline Consolidation & $\begin{array}{l}\text { RAPID0 trial [82] } \\
\text { (NCT01558921) }\end{array}$ & Phase III RCT & 842 & $\begin{array}{l}\text { Standard long course CRT } \rightarrow \text { surgery } \\
\rightarrow \text { optional adjuvant CAPOX }(8 \times) \\
\text { SC-RT ( } 5 \text { Gy } \times 5) \rightarrow \text { CAPOX }(6 \times) \rightarrow \\
\quad \text { surgery }\end{array}$ & 3-yr DFS & $\begin{array}{l}\text { Toxicity, R0 resection rate, pCR, QoL, } \\
\text { functional outcome, OS }\end{array}$ \\
\hline Consolidation & $\begin{array}{r}\text { TRIGGER trial [65] } \\
\text { (NCT02704520) }\end{array}$ & Phase III RCT & 633 & Refer to Fig. 1 & $\begin{array}{l}\text { The rate of patient } \\
\text { recruitment and } \\
\text { randomization }\end{array}$ & $\begin{array}{l}\text { Rate of unit recruitment, toxicity, } \\
\text { reproducibility of mrTRG reporting, } \\
\text { surgical morbidity, pCR, residual } \\
\text { tumor density, surgical quality rates }\end{array}$ \\
\hline $\begin{array}{l}\text { Consolidation or } \\
\text { induction }\end{array}$ & $\begin{array}{l}\text { Smith et al. [82] } \\
\text { (NCT02008656) }\end{array}$ & Phase II RCT & 202 & $\begin{array}{l}\text { Induction CTx + CRT } \\
\text { CRT + consolidation CTx }\end{array}$ & 3-yr RFS & $\begin{array}{l}\text { Organ preservation rate, compliance, } \\
\text { toxicity, functional outcome, QoL }\end{array}$ \\
\hline TNT without RT & $\begin{array}{l}\text { PROSPECT [84] } \\
\text { (NCT01515787) }\end{array}$ & Phase III RCT & 1,060 & $\begin{array}{l}5 \text {-FU }+ \text { CRT } \rightarrow \text { surgery } \rightarrow \text { FOLFOX }(8 \times) \\
\text { FOLFOX }(6 \times) \rightarrow \text { tumor response } \\
\text { assessment } \rightarrow \text { TME or CRT } \\
\text { Adjuvant therapy if } \\
\text { R0 } \rightarrow \text { FOLFOX }(6 \times) \\
\text { R } 1+\rightarrow \text { FOLFOX }(4 \times)+\text { CRT }\end{array}$ & R0 rate, DFS, LRR & $\mathrm{pCR}, \mathrm{OS}$, toxicity, rate of CRT \\
\hline TNT without RT & $\begin{array}{l}\text { BACCHUS [85] } \\
\text { (NCT01650428) }\end{array}$ & Phase II RCT & 60 & $\begin{array}{l}\text { FOLFOX + bev } \\
\text { FOLFOXIRI + bev }\end{array}$ & $\mathrm{pCR}$ rate & $\begin{array}{l}\text { Response rate; CRM negative } \\
\text { resection; T and } \mathrm{N} \text { downstaging; } \\
\text { PFS, DFS, OS, LRR; 1-yr colostomy } \\
\text { rate; toxicity, compliance }\end{array}$ \\
\hline
\end{tabular}

TNT, total neoadjuvant therapy; RCT, randomized controlled trial; CRT, chemoradiotherapy; CTx, chemotherapy; SC-RT, short-course radiotherapy; Gy, gray; CAPOX, capecitabine/oxaliplatin; 5-FU, 5-fluorouracil; Cape, capecitabine; FOLFOXIRI, oxaliplatin/5-FU/irinotecan; bev, bevacizumab; DFS, disease-free survival; mFOLFOX6, modified 5-fluorouracil, leucovorin, and oxaliplatin; OS, overall survival; mrTRG, magnetic resonance tumor regression grade; PFS, progression free survival; LRR, local recurrence rate; $\mathrm{RO}$, microscopically clear resection; QoL, quality of life.

group was not different, the authors concluded that the evidence is insufficient to draw a firm conclusion on the oncological safety of the current organ preservation strategy. Other experts express a similar opinion on the previous studies on organ preservation approach, criticizing the significant heterogeneity of data and methods of research [74].

Furthermore, delaying surgery may impose detrimental effect in the patients who require surgical treatment after neoadjuvant CRT. A multicentered, randomized trial, GRECCAR-6 trial, investigated the effect of increasing the delay period between nCRT and surgery [75]. The investigators found that increased morbidity and a poor quality of TME was seen in the patients in longer waiting period of 11 weeks compared to the patients in standard waiting period of 7 weeks. They concluded that a longer waiting period may be associated with higher morbidity and more difficult surgical resection. The optimal interval for waiting period and timing for re-assessment is unanswered. Further research is needed to determine the risk and benefit of prolonged interval between $\mathrm{nCRT}$ and surgery.

Salvage TME for the regrowth after full-thickness local excision seems to impose a significant threat, jeopardizing the oncologic principle. A retrospective study on patients who underwent salvage TME after nCRT and subsequent local excision demonstrates that salvage TME was associated with $87.5 \%$ of circumferential resection margin positivity and $40 \%$ of the local re-recurrence rate at two years [76]. Fibrosis and scar tissue may disrupt the surgical plane, extending into or beyond the mesorectal fascia; thus, the optimal TME cannot be achieved when it's needed [72]. 
Whether or not the salvage TME is sufficient for surgical and oncological outcome remains to be clarified.

\section{TOTAL NEOADJUVANT THERAPY AND ORGAN PRESERVATION}

The National Comprehensive Cancer Network (NCCN) guidelines for locally advanced rectal cancer have recommended a multidisciplinary approach with neoadjuvant CRT followed by a radical surgery, with TME principle approach, then adjuvant chemotherapy [26]. However, as mentioned before, due to low compliance and uncertain survival benefits of adjuvant chemotherapy, many clinicians and researchers have planned trials to test the "total neoadjuvant therapy" approach, in which all planned radiation therapy or chemotherapy is delivered preoperatively [77]. Combining induction and consolidation chemotherapy with oxaliplatin-based regimen along with oral or intravenous 5-FU seems to improve the $\mathrm{pCR}$ rate and compliance without a significant increase in the toxicity [41, 42, 44, 77-80]. Other randomized controlled trials, such as the TRIGGER trial [65], the RAPIDO trial [81], a phase II trial by MSKCC [82], the KONCLUDE trial [83], and others [84-86], are ongoing to find a feasible and effective regimen that achieves good oncologic outcome and high organ preservation rate, as shown in Table 3. These trials are anticipated to provide better understanding of tumor characteristics and behavior, which will lead to the development of selection criteria for patients that are the optimal candidate for organ preservation. One caution of delivering total neoadjuvant therapy is that the potential to increase toxicity should be carefully addressed.

\section{CONCLUSION}

The idea of organ preservation in rectal cancer management is a radical concept which alters the fundamental belief of anatomical eradication in cancer treatment. Tremendous interest and desire for organ preservation in rectal cancer are partly driven by the yearning of patients who want to preserve a decent quality of life in the modern era. A large volume of concurrent evidence that organ-preservation strategy is as safe as stand TME is currently lacking. Clinicians and surgeons should carefully follow the evidence to advisee individual patient, offering the most reliable treatment option that satisfies the need of patients. Upcoming results from multiple ongoing and future trials are anticipated to provide insight for clinical decisions about the optimal oncologic outcome as well as improved quality of life.

\section{CONFLICT OF INTEREST}

No potential conflict of interest relevant to this article was reported.

\section{REFERENCES}

1. Heald RJ. The 'Holy Plane' of rectal surgery. J R Soc Med 1988; 81:503-8.

2. Heald RJ, Ryall RD. Recurrence and survival after total mesorectal excision for rectal cancer. Lancet (London, England) 1986;1: 1479-82.

3. Havenga K, Enker WE, Norstein J, Moriya Y, Heald RJ, van Houwelingen HC, et al. Improved survival and local control after total mesorectal excision or D3 lymphadenectomy in the treatment of primary rectal cancer: an international analysis of 1411 patients. Eur J Surg Oncol 1999;25:368-74.

4. Ruo L, Guillem JG. Major 20th-century advancements in the management of rectal cancer. Dis Colon Rectum 1999;42:563-78.

5. van Gijn W, Marijnen CA, Nagtegaal ID, Kranenbarg EM, Putter $\mathrm{H}$, Wiggers T, et al. Preoperative radiotherapy combined with total mesorectal excision for resectable rectal cancer: 12-year follow-up of the multicentre, randomised controlled TME trial. Lancet Oncol 2011;12:575-82.

6. Rodel C, Liersch T, Becker H, Fietkau R, Hohenberger W, Hothorn T, et al. Preoperative chemoradiotherapy and postoperative chemotherapy with fluorouracil and oxaliplatin versus fluorouracil alone in locally advanced rectal cancer: initial results of the German CAO/ARO/AIO-04 randomised phase 3 trial. Lancet Oncol 2012;13:679-87.

7. Pahlman L, Glimelius B. Pre- or postoperative radiotherapy in rectal and rectosigmoid carcinoma. Report from a randomized multicenter trial. Ann Surg 1990;211:187-95.

8. Hyams DM, Mamounas EP, Petrelli N, Rockette H, Jones J, Wieand HS, et al. A clinical trial to evaluate the worth of preoperative multimodality therapy in patients with operable carcinoma of the rectum: a progress report of National Surgical Breast and Bowel Project Protocol R-03. Dis Colon Rectum 1997;40:131-9.

9. Gerard JP, Conroy T, Bonnetain F, Bouche O, Chapet O, ClosonDejardin MT, et al. Preoperative radiotherapy with or without concurrent fluorouracil and leucovorin in T3-4 rectal cancers: results of FFCD 9203. J Clin Oncol 2006;24:4620-5.

10. Bosset JF, Collette L, Calais G, Mineur L, Maingon P, RadosevicJelic $\mathrm{L}$, et al. Chemotherapy with preoperative radiotherapy in rectal cancer. New Engl J Med 2006;355:1114-23.

11. Rutten HJ, den Dulk M, Lemmens VE, van de Velde CJ, Marijnen CA. Controversies of total mesorectal excision for rectal cancer in elderly patients. Lancet Oncol 2008;9:494-501.

12. Juul T, Ahlberg M, Biondo S, Espin E, Jimenez LM, Matzel KE, et al. Low anterior resection syndrome and quality of life: an international multicenter study. Dis Colon Rectum 2014;57:585-91.

13. Downing A, Glaser AW, Finan PJ, Wright P, Thomas JD, Gilbert A, et al. Functional outcomes and health-related quality of life following curative treatment for rectal cancer: a population-level study in England. Int J Rad Oncol Biol Phys 2019;103:1132-42.

14. Sun V, Grant M, Wendel CS, McMullen CK, Bulkley JE, Herrinton LJ, et al. Sexual function and health-related quality of life in 
long-term rectal cancer survivors. J Sex Med 2016;13:1071-9.

15. Cotte E, Passot G, Decullier E, Maurice C, Glehen O, Francois Y, et al. Pathologic response, when increased by longer interval, is a marker but not the cause of good prognosis in rectal cancer: 17year follow-up of the Lyon R90-01 randomized trial. Int J Rad Oncol Biol Phys 2016;94:544-53.

16. Hartley A, Ho KF, McConkey C, Geh JI. Pathological complete response following pre-operative chemoradiotherapy in rectal cancer: analysis of phase II/III trials. British J Radiol 2005;78:9348.

17. Sanghera P, Wong DW, McConkey CC, Geh JI, Hartley A. Chemoradiotherapy for rectal cancer: an updated analysis of factors affecting pathological response. Clin Oncol (R Coll Radiolo) 2008;20:176-83.

18. Park IJ, You YN, Agarwal A, Skibber JM, Rodriguez-Bigas MA, Eng C, et al. Neoadjuvant treatment response as an early response indicator for patients with rectal cancer. Journal Clin Oncol 2012; 30:1770-6.

19. Hofheinz RD, Wenz F, Post S, Matzdorff A, Laechelt S, Hartmann JT, et al. Chemoradiotherapy with capecitabine versus fluorouracil for locally advanced rectal cancer: a randomised, multicentre, non-inferiority, phase 3 trial. Lancet Oncol 2012;13:579-88.

20. O'Connell MJ, Colangelo LH, Beart RW, Petrelli NJ, Allegra CJ, Sharif S, et al. Capecitabine and oxaliplatin in the preoperative multimodality treatment of rectal cancer: surgical end points from National Surgical Adjuvant Breast and Bowel Project trial R-04. Journal Clin Oncol 2014;32:1927-34.

21. Aschele C, Cionini L, Lonardi S, Pinto C, Cordio S, Rosati G, et al. Primary tumor response to preoperative chemoradiation with or without oxaliplatin in locally advanced rectal cancer: pathologic results of the STAR-01 randomized phase III trial. J Clin Oncol 2011;29:2773-80.

22. Gerard JP, Azria D, Gourgou-Bourgade S, Martel-Laffay I, Hennequin C, Etienne PL, et al. Comparison of two neoadjuvant chemoradiotherapy regimens for locally advanced rectal cancer: results of the phase III trial ACCORD 12/0405-Prodige 2. J Clin Oncol 2010;28:1638-44.

23. Prolongation of the disease-free interval in surgically treated rectal carcinoma. New England J Med 1985;312:1465-72.

24. Fisher B, Wolmark N, Rockette H, Redmond C, Deutsch M, Wickerham DL, et al. Postoperative adjuvant chemotherapy or radiation therapy for rectal cancer: results from NSABP protocol R-01. J Natl Cancer Inst 1988;80:21-9.

25. Benson AB 3rd, Venook AP, Al-Hawary MM, Cederquist L, Chen YJ, Ciombor KK, et al. Rectal cancer, version 2.2018, NCCN clinical practice guidelines in oncology. J Natl Cancer Inst 2018;16:874901.

26. Benson AB 3rd, Bekaii-Saab T, Chan E, Chen YJ, Choti MA, Cooper HS, et al. Rectal cancer. J Natl Cancer Inst 2012;10:1528-64.

27. Moertel CG, Fleming TR, Macdonald JS, Haller DG, Laurie JA, Goodman PJ, et al. Levamisole and fluorouracil for adjuvant therapy of resected colon carcinoma. New Engl J Med 1990;322:
352-8.

28. Andre T, Boni C, Navarro M, Tabernero J, Hickish T, Topham C, et al. Improved overall survival with oxaliplatin, fluorouracil, and leucovorin as adjuvant treatment in stage II or III colon cancer in the MOSAIC trial. Journal Clin Oncol 2009;27:3109-16.

29. Petersen SH, Harling H, Kirkeby LT, Wille-Jorgensen P, Mocellin S. Postoperative adjuvant chemotherapy in rectal cancer operated for cure. Cochrane Database Syst Rev 2012;(3):CD004078.

30. Breugom AJ, Swets M, Bosset JF, Collette L, Sainato A, Cionini L, et al. Adjuvant chemotherapy after preoperative (chemo)radiotherapy and surgery for patients with rectal cancer: a systematic review and meta-analysis of individual patient data. Lancet Oncol 2015;16:200-7.

31. Taal BG, Van Tinteren H, Zoetmulder FA. Adjuvant 5FU plus levamisole in colonic or rectal cancer: improved survival in stage II and III. British J Cancer 2001;85:1437-43.

32. Bosset JF, Calais G, Mineur L, Maingon P, Stojanovic-Rundic S, Bensadoun RJ, et al. Fluorouracil-based adjuvant chemotherapy after preoperative chemoradiotherapy in rectal cancer: long-term results of the EORTC 22921 randomised study. Lancet Oncol 2014;15:184-90.

33. Engelen SM, Maas M, Lahaye MJ, Leijtens JW, van Berlo CL, Jansen RL, et al. Modern multidisciplinary treatment of rectal cancer based on staging with magnetic resonance imaging leads to excellent local control, but distant control remains a challenge. Eur J Cancer 2013;49:2311-20.

34. Khrizman P, Niland JC, ter Veer A, Milne D, Bullard Dunn K, Carson WE 3rd, et al. Postoperative adjuvant chemotherapy use in patients with stage II/III rectal cancer treated with neoadjuvant therapy: a national comprehensive cancer network analysis. J Clin Oncol 2013;31:30-8.

35. Biagi JJ, Raphael MJ, Mackillop WJ, Kong W, King WD, Booth CM. Association between time to initiation of adjuvant chemotherapy and survival in colorectal cancer: a systematic review and meta-analysis. JAMA 2011;305:2335-42.

36. Glynne-Jones R, Grainger J, Harrison M, Ostler P, Makris A. Neoadjuvant chemotherapy prior to preoperative chemoradiation or radiation in rectal cancer: should we be more cautious? British J Cancer 2006;94:363-71.

37. Calvo FA, Serrano FJ, Diaz-Gonzalez JA, Gomez-Espi M, Lozano E, Garcia R, et al. Improved incidence of pT0 downstaged surgical specimens in locally advanced rectal cancer (LARC) treated with induction oxaliplatin plus 5-fluorouracil and preoperative chemoradiation. Ann Oncol 2006;17:1103-10.

38. Chau I, Brown G, Cunningham D, Tait D, Wotherspoon A, Norman AR, et al. Neoadjuvant capecitabine and oxaliplatin followed by synchronous chemoradiation and total mesorectal excision in magnetic resonance imaging-defined poor-risk rectal cancer. J Clin Oncol 2006;24:668-74.

39. Fernandez-Martos C, Pericay C, Aparicio J, Salud A, Safont M, Massuti B, et al. Phase II, randomized study of concomitant chemoradiotherapy followed by surgery and adjuvant capecitabine plus 
oxaliplatin (CAPOX) compared with induction CAPOX followed by concomitant chemoradiotherapy and surgery in magnetic resonance imaging-defined, locally advanced rectal cancer: Grupo cancer de recto 3 study. J Clin Oncol 2010; 28:859-65.

40. Marechal R, Vos B, Polus M, Delaunoit T, Peeters M, Demetter P, et al. Short course chemotherapy followed by concomitant chemoradiotherapy and surgery in locally advanced rectal cancer: a randomized multicentric phase II study. Ann Oncol 2012;23: 1525-30.

41. Schou JV, Larsen FO, Rasch L, Linnemann D, Langhoff J, Hogdall $\mathrm{E}$, et al. Induction chemotherapy with capecitabine and oxaliplatin followed by chemoradiotherapy before total mesorectal excision in patients with locally advanced rectal cancer. Ann Oncol 2012;23:2627-33.

42. Cercek A, Goodman KA, Hajj C, Weisberger E, Segal NH, ReidyLagunes DL, et al. Neoadjuvant chemotherapy first, followed by chemoradiation and then surgery, in the management of locally advanced rectal cancer. J Natl Compr Cancer Netw 2014;12:513-9.

43. Garcia-Aguilar J, Chow OS, Smith DD, Marcet JE, Cataldo PA, Varma MG, et al. Effect of adding mFOLFOX6 after neoadjuvant chemoradiation in locally advanced rectal cancer: a multicentre, phase 2 trial. Lancet Oncol 2015;16:957-66.

44. Marco MR, Zhou L, Patil S, Marcet JE, Varma MG, Oommen S, et al. Consolidation mFOLFOX6 chemotherapy after chemoradiotherapy improves survival in patients with locally advanced rectal cancer: final results of a multicenter phase II trial. Dis Colon Rectum 2018;61:1146-55.

45. Bujko K, Wyrwicz L, Rutkowski A, Malinowska M, Pietrzak L, Krynski J, et al. Long-course oxaliplatin-based preoperative chemoradiation versus $5 \times 5 \mathrm{~Gy}$ and consolidation chemotherapy for cT4 or fixed cT3 rectal cancer: results of a randomized phase III study. Ann Oncol 2016;27:834-42.

46. Gao YH, An X, Sun WJ, Cai J, Cai MY, Kong LH, et al. Evaluation of capecitabine and oxaliplatin administered prior to and then concomitant to radiotherapy in high risk locally advanced rectal cancer. J Surg Oncol 2014;109:478-82.

47. Zhu J, Gu W, Lian P, Sheng W, Cai G, Shi D, et al. A phase II trial of neoadjuvant IMRT-based chemoradiotherapy followed by one cycle of capecitabine for stage II/III rectal adenocarcinoma. Rad Oncol 2013;8:130.

48. Habr-Gama A, Perez RO, Nadalin W, Sabbaga J, Ribeiro U Jr, Silva e Sousa AH Jr, et al. Operative versus nonoperative treatment for stage 0 distal rectal cancer following chemoradiation therapy: long-term results. Ann Surg 2004;240:711-7.

49. Maas M, Beets-Tan RG, Lambregts DM, Lammering G, Nelemans PJ, Engelen SM, et al. Wait-and-see policy for clinical complete responders after chemoradiation for rectal cancer. J Clin Oncol 2011;29:4633-40.

50. Smith JD, Ruby JA, Goodman KA, Saltz LB, Guillem JG, Weiser $\mathrm{MR}$, et al. Nonoperative management of rectal cancer with complete clinical response after neoadjuvant therapy. Ann Surg 2012; 256:965-72.
51. Maas M, Nelemans PJ, Valentini V, Das P, Rodel C, Kuo LJ, et al. Long-term outcome in patients with a pathological complete response after chemoradiation for rectal cancer: a pooled analysis of individual patient data. Lancet Oncol 2010;11:835-44.

52. Sao Juliao GP, Habr-Gama A, Vailati BB, Araujo SE, Fernandez LM, Perez RO. New strategies in rectal cancer. Surgical Clin North Am 2017;97:587-604.

53. Habr-Gama A, Gama-Rodrigues J, Sao Juliao GP, Proscurshim I, Sabbagh C, Lynn PB, et al. Local recurrence after complete clinical response and watch and wait in rectal cancer after neoadjuvant chemoradiation: impact of salvage therapy on local disease control. Int J Rad Oncol Biol Phys 2014;88:822-8.

54. Perez RO, Habr-Gama A, Sao Juliao GP, Lynn PB, Sabbagh C, Proscurshim I, et al. Predicting complete response to neoadjuvant CRT for distal rectal cancer using sequential PET/CT imaging. Techn Coloproctol 2014;18:699-708.

55. Lai CL, Lai MJ, Wu CC, Jao SW, Hsiao CW. Rectal cancer with complete clinical response after neoadjuvant chemoradiotherapy, surgery, or "watch and wait". Int J Colorectal Dis 2016;31:413-9.

56. Renehan AG, Malcomson L, Emsley R, Gollins S, Maw A, Myint AS, et al. Watch-and-wait approach versus surgical resection after chemoradiotherapy for patients with rectal cancer (the OnCoRe project): a propensity-score matched cohort analysis. Lancet Oncol 2016;17:174-83.

57. Vaccaro CA, Yazyi FJ, Ojra Quintana G, Santino JP, Sardi ME, Beder D, et al. Locally advanced rectal cancer: preliminary results of rectal preservation after neoadjuvant chemoradiotherapy. Cir Esp 2016;94:274-9.

58. Appelt AL, Ploen J, Harling H, Jensen FS, Jensen LH, Jorgensen JC, et al. High-dose chemoradiotherapy and watchful waiting for distal rectal cancer: a prospective observational study. Lancet Oncol 2015;16:919-27.

59. Dattani M, Heald RJ, Goussous G, Broadhurst J, Sao Juliao GP, Habr-Gama A, et al. Oncological and survival outcomes in watch and wait patients with a clinical complete response after neoadjuvant chemoradiotherapy for rectal cancer: a systematic review and pooled analysis. Ann Surg 2018;268:955-67.

60. Al-Sukhni E, Milot L, Fruitman M, Beyene J, Victor JC, Schmocker S, et al. Diagnostic accuracy of MRI for assessment of T category, lymph node metastases, and circumferential resection margin involvement in patients with rectal cancer: a systematic review and meta-analysis. Ann Surg Oncol 2012;19:2212-23.

61. Patel UB, Brown G, Rutten H, West N, Sebag-Montefiore D, Glynne-Jones R, et al. Comparison of magnetic resonance imaging and histopathological response to chemoradiotherapy in locally advanced rectal cancer. Annals Surg Oncol 2012;19:2842-52.

62. Patel UB, Blomqvist LK, Taylor F, George C, Guthrie A, Bees N, et al. MRI after treatment of locally advanced rectal cancer: how to report tumor response--the MERCURY experience. AJR Am J Roentgenol 2012;199:W486-95.

63. Bhoday J, Smith F, Siddiqui MR, Balyasnikova S, Swift RI, Perez R, et al. Magnetic resonance tumor regression grade and residual 
mucosal abnormality as predictors for pathological complete response in rectal cancer postneoadjuvant chemoradiotherapy. Dis Colon Rectum 2016;59:925-33.

64. van der Paardt MP, Zagers MB, Beets-Tan RG, Stoker J, Bipat S. Patients who undergo preoperative chemoradiotherapy for locally advanced rectal cancer restaged by using diagnostic MR imaging: a systematic review and meta-analysis. Radiology 2013;269:10112.

65. Battersby NJ, Dattani M, Rao S, Cunningham D, Tait D, Adams R, et al. A rectal cancer feasibility study with an embedded phase III trial design assessing magnetic resonance tumour regression grade (mrTRG) as a novel biomarker to stratify management by good and poor response to chemoradiotherapy (TRIGGER): study protocol for a randomised controlled trial. Trials 2017;18:394.

66. Verseveld M, de Graaf EJ, Verhoef C, van Meerten E, Punt CJ, de Hingh IH, et al. Chemoradiation therapy for rectal cancer in the distal rectum followed by organ-sparing transanal endoscopic microsurgery (CARTS study). Br J Surg 2015;102:853-60.

67. Stijns RCH, de Graaf EJR, Punt CJA, Nagtegaal ID, Nuyttens J, van Meerten E, et al. Long-term oncological and functional outcomes of chemoradiotherapy followed by organ-sparing transanal endoscopic microsurgery for distal rectal cancer: The CARTS study. JAMA Surg 2019;154:47-54.

68. Lezoche E, Baldarelli M, Lezoche G, Paganini AM, Gesuita R, Guerrieri M. Randomized clinical trial of endoluminal locoregional resection versus laparoscopic total mesorectal excision for T2 rectal cancer after neoadjuvant therapy. Bri J Surg 2012;99: 1211-8.

69. Hallam S, Messenger DE, Thomas MG. A systematic review of local excision after neoadjuvant therapy for rectal cancer: are ypT0 tumors the limit? Dis Colon Rectum 2016;59:984-97.

70. Dewdney A, Cunningham D, Tabernero J, Capdevila J, Glimelius B, Cervantes A, et al. Multicenter randomized phase II clinical trial comparing neoadjuvant oxaliplatin, capecitabine, and preoperative radiotherapy with or without cetuximab followed by total mesorectal excision in patients with high-risk rectal cancer (EXPERT-C). J Clin Oncol 2012;30:1620-7.

71. Perez RO, Habr-Gama A, Sao Juliao GP, Proscurshim I, Scanavini Neto A, Gama-Rodrigues J. Transanal endoscopic microsurgery for residual rectal cancer after neoadjuvant chemoradiation therapy is associated with significant immediate pain and hospital readmission rates. Dis Colon Rectum 2011;54:545-51.

72. Beets GL, Figueiredo NF, Beets-Tan RG. Management of rectal cancer without radical resection. Ann Rev Med 2017;68:169-82.

73. Kong JC, Guerra GR, Warrier SK, Ramsay RG, Heriot AG. Outcome and salvage surgery following "watch and wait" for rectal cancer after neoadjuvant therapy: a systematic review. Dis Colon Rectum 2017;60:335-45.

74. Bernier L, Balyasnikova S, Tait D, Brown G. Watch-and-wait as a therapeutic strategy in rectal cancer. Curr Colorectal Cancer Rep 2018;14:37-55.

75. Lefevre JH, Mineur L, Kotti S, Rullier E, Rouanet P, de Chaisemar- tin C, et al. Effect of interval ( 7 or 11 weeks) between neoadjuvant radiochemotherapy and surgery on complete pathologic response in rectal cancer: a multicenter, randomized, controlled trial (GRECCAR-6). J Clin Oncol 2016;34:3773-80.

76. Perez RO, Habr-Gama A, Sao Juliao GP, Proscurshim I, Fernandez LM, de Azevedo RU, et al. Transanal endoscopic microsurgery (TEM) following neoadjuvant chemoradiation for rectal cancer: outcomes of salvage resection for local recurrence. Ann Surg Oncol 2016;23:1143-8.

77. Ludmir EB, Palta M, Willett CG, Czito BG. Total neoadjuvant therapy for rectal cancer: An emerging option. Cancer 2017;123: 1497-506.

78. Fernandez-Martos C, Garcia-Albeniz X, Pericay C, Maurel J, Aparicio J, Montagut $\mathrm{C}$, et al. Chemoradiation, surgery and adjuvant chemotherapy versus induction chemotherapy followed by chemoradiation and surgery: long-term results of the Spanish GCR-3 phase II randomized trialdagger. Ann Oncol 2015;26: $1722-8$.

79. Cercek A, Roxburgh CSD, Strombom P, Smith JJ, Temple LK, Nash GM, et al. Adoption of total neoadjuvant therapy for locally advanced rectal cancer. JAMA Oncol 2018;4:e180071.

80. Gollins S, West N, Sebag-Montefiore D, Susnerwala S, Falk S, Brown N, et al. A prospective phase II study of pre-operative chemotherapy then short-course radiotherapy for high risk rectal cancer: COPERNICUS. Br J cancer 2018;119:697-706.

81. Nilsson PJ, van Etten B, Hospers GA, Pahlman L, van de Velde CJ, Beets-Tan RG, et al. Short-course radiotherapy followed by neo-adjuvant chemotherapy in locally advanced rectal cancer-the RAPIDO trial. BMC Cancer 2013;13:279.

82. Smith JJ, Chow OS, Gollub MJ, Nash GM, Temple LK, Weiser MR, et al. Organ Preservation in Rectal Adenocarcinoma: a phase II randomized controlled trial evaluating 3-year disease-free survival in patients with locally advanced rectal cancer treated with chemoradiation plus induction or consolidation chemotherapy, and total mesorectal excision or nonoperative management. BMC Cancer 2015;15:767.

83. Kim CW, Kang BM, Kim IY, Kim JY, Park SJ, Park WC, et al. Korean Society of Coloproctology (KSCP) trial of cONsolidation Chemotherapy for Locally advanced mid or low rectal cancer after neoadjUvant concurrent chemoraDiothErapy: a multicenter, randomized controlled trial (KONCLUDE). BMC Cancer 2018; 18:538.

84. Schrag D, Weiser MR, Goodman KA, Gonen M, Hollywood E, Cercek A, et al. Neoadjuvant chemotherapy without routine use of radiation therapy for patients with locally advanced rectal cancer: a pilot trial. J Clin Oncol 2014;32:513-8.

85. Glynne-Jones R, Hava N, Goh V, Bosompem S, Bridgewater J, Chau I, et al. Bevacizumab and Combination Chemotherapy in rectal cancer Until Surgery (BACCHUS): a phase II, multicentre, open-label, randomised study of neoadjuvant chemotherapy alone in patients with high-risk cancer of the rectum. BMC Cancer 2015;15:764. 
86. Deng Y, Chi P, Lan P, Wang L, Chen W, Cui L, et al. Modified FOLFOX6 with or without radiation versus fluorouracil and leucovorin with radiation in neoadjuvant treatment of locally ad- vanced rectal cancer: initial results of the Chinese FOWARC multicenter, open-label, randomized three-arm phase III trial. J Clin Oncol 2016;34:3300-7. 